\title{
Investigation on Microblasting Applied to CrN Coatings
}

\author{
Lorenzo Montesano, Annalisa Pola, Marcello Gelfi, and Giovina Marina La Vecchia
}

Department of Mechanical and Industrial Engineering, University of Brescia, 25123 Brescia, Italy

Correspondence should be addressed to Lorenzo Montesano; lorenzo.montesano@unibs.it

Received 4 February 2016; Accepted 13 March 2016

Academic Editor: Gianluca Cicala

Copyright (C) 2016 Lorenzo Montesano et al. This is an open access article distributed under the Creative Commons Attribution License, which permits unrestricted use, distribution, and reproduction in any medium, provided the original work is properly cited.

A microblasting treatment carried out on CrN coated samples was studied to investigate the induced effect on corrosion and wear resistance. $\mathrm{CrN}$ coating was deposited through Cathodic Arc Evaporation technique on quenched and tempered steel. The properties of the coating were studied by hardness measurements, scratch, potentiodynamic, and pin-on-disk tests. The results show that microblasting reduces the corrosion resistance while improving the wear behavior.

\section{Introduction}

Physical Vapor Deposition (PVD) coatings are widely used to increase the wear and corrosion resistance of many substrates $[1,2]$ and for different applications $[3,4]$. As known, in fact, the presence of a ceramic layer increases the hardness of the surface and reduces the friction coefficient [2]. Additionally, due to the chemical stability of the deposited material, the corrosion of the substrate is strongly reduced $[1,2]$.

Different authors have already demonstrated that the corrosion resistance of a coated part is influenced by the presence of defects formed during the deposition process, such as pores or droplets [5-7]. It follows that the removal of coating defects, without affecting other coating properties, can be an interesting method to enhance corrosion resistance [1].

The microblasting of the film surface has been proven to remove droplets from Cathodic Arc Evaporation (CAE) coating surface, without reducing the adhesion or the mechanical properties of the coating itself [8]. This technique is commercially used to clean the surface of each layer during multilayer depositions, by removing some defects that have a detrimental effect on layers adhesion.

Authors also stated that microblasting, performed with the correct parameters, extends the life of cutting tools in the case of TiAlN coated cemented carbide inserts [9-12]. Additionally, a study on $\mathrm{CrN}$ deposited on steel demonstrates that the fatigue resistance is enhanced after the mechanical surface treatment, due to the increase in the residual compressive stress of the substrate skin [13]. As known, in fact, the fatigue cracks in PVD coated parts nucleate at the interface between coating and substrate $[14,15]$.

To the authors' knowledge, no research works correlating microblasting with corrosion and wear resistance of CAE $\mathrm{CrN}$ coatings have been published. Therefore, the aim of this paper is to investigate these properties on a $4 \mu \mathrm{m} \mathrm{CrN} \mathrm{coat-}$ ing, deposited on quenched and tempered steel and subjected to microblasting. A first set of tests was performed to identify the correct microblasting parameters. The properties of the coating after microblasting were then assessed by means of hardness measurements, scratch, potentiodynamic, and pin-on-disk tests. The results were also compared to those obtained for the as-deposited state.

\section{Materials and Methods}

The specimens were machined from quenched and tempered steel, whose hardness is $400 \mathrm{HB}$. In Table 1 the chemical composition of the steel is reported.

Wear and corrosion test samples were cut as disks of $40 \mathrm{~mm}$ and $18 \mathrm{~mm}$ in diameter, respectively. In both cases, the flat surfaces were polished up to mirror finishing.

$\mathrm{CrN}$ deposition was carried out with a Metaplast system, working in a nitrogen atmosphere with a pressure of 1.4 $\times 10^{-2}$ bar. Cathode power and bias were set at $60 \mathrm{Ah}$ 
TABLE 1: Chemical composition (wt\%) of the steel substrate.

\begin{tabular}{lcccccccccccc}
\hline $\mathrm{C}$ & $\mathrm{S}$ & $\mathrm{P}$ & $\mathrm{Mn}$ & $\mathrm{Cr}$ & $\mathrm{Ni}$ & $\mathrm{Mo}$ & $\mathrm{Cu}$ & $\mathrm{Si}$ & $\mathrm{V}$ & $\mathrm{Al}$ & $\mathrm{Fe}$ \\
\hline 0.283 & 0.002 & 0.008 & 0.623 & 0.850 & 3.065 & 0.506 & 0.167 & 0.312 & 0.093 & 0.023 & $\mathrm{Bal}$ \\
\hline
\end{tabular}

and $80 \mathrm{~V}$, respectively. Before the deposition, argon etching was performed with a bias of $200 \mathrm{~V}$. The obtained coating thickness was $4 \mu \mathrm{m}$, as resulting by Calotest measurements.

After the coating deposition, dry microblasting (MB) was carried out with silica microspheres, having a diameter ranging between 70 and $100 \mu \mathrm{m}$ and a mean hardness of $47 \mathrm{HRC}$. The nozzle angle was set at $90^{\circ}$ with respect to the coating surface. Three blasting pressures were used $(2,3$, and 6 bar) with the aim of identifying the maximum pressure able to modify the surface without causing damage of the coating.

In order to understand the effect of the microblasting on tribological and corrosion resistance of the investigated coating, three groups of samples were considered:

(i) bare steel (named BS);

(ii) coated samples without microblasting treatment (named CrN);

(iii) coated samples with microblasting treatment (named $\mathrm{CrN}+\mathrm{MB})$.

A mechanical characterization of the coating was performed on the samples with and without microblasting. Nanoindentation and elastic modulus were obtained through a Table Top Nanoindentation Tester (TTX-NHT) of CSM Instruments. The maximum load $(50 \mathrm{mN})$ was chosen in order to maintain the penetration depth lower than $10 \%$ of the coating thickness, thus excluding any substrate interferences $[16,17]$. In order to obtain a statistical value, at least 20 indentations were carried out on each sample.

Scratch tests were done with a Revetest by CSM Instruments equipped with a Rockwell indenter with a tip radius of $200 \mu \mathrm{m}$. Two critical loads were defined to evaluate the coating adhesion: LC1, corresponding to the detection of the first lateral crack (cohesive failure), and LC2, which is related to the observation of complete substrate exposure (adhesive failure).

Substrate residual stresses were measured by means of $\mathrm{X}$-Stress Analyzer Rigaku Strainflex with $\mathrm{CrK} \alpha$ radiation. The stress values were calculated applying the well-known $d-\sin ^{2} \Psi$ method, which considers the $2 \theta$ shift of steel (211) peak [18].

Scanning Electron Microscope (SEM) analyses of the coating surfaces were performed with a LEO EVO 40, equipped with an Energy Dispersive Spectroscopy probe (EDS).

Corrosion tests were made in $3.5 \% \mathrm{NaCl}$ solution with AMEL 7050 potentiostat, considering a potential between -0.8 and $+1.5 \mathrm{~V}$, in order to observe both Tafel region and passivation/pitting phenomena. Three tests for each sample configuration were executed. Corrosion current density $\left(i_{0}\right)$ and free corrosion potential $\left(E_{0}\right)$ were extrapolated by considering the tangent at both cathodic and anodic branches of the potentiodynamic curves. Coating porosity was also calculated according to the method reported in [19].

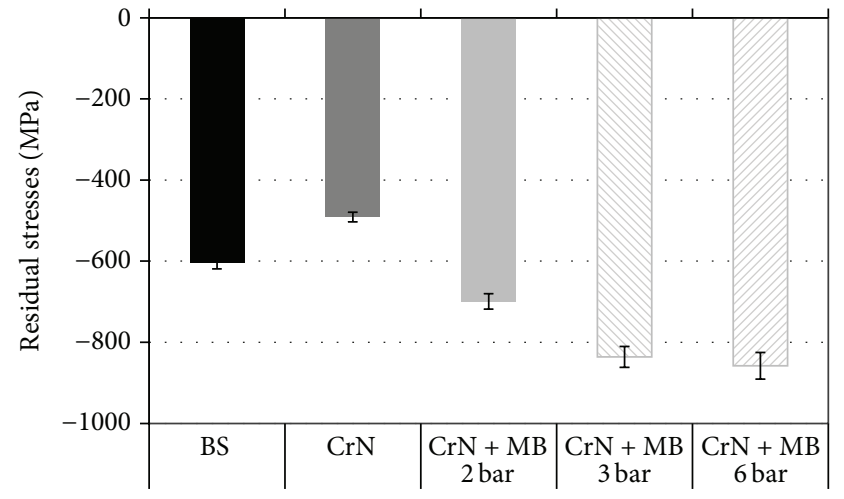

FIGURE 1: Residual stress measurements in the steel substrate.

Finally, the tribological behavior of the samples was studied with a pin-on-disk tribometer (CSM instrument), using alumina balls of $6 \mathrm{~mm}$ in diameter as counterparts. The sliding distance and the track radius were set, respectively, at $4 \mathrm{~cm} / \mathrm{s}$ and $3 \mathrm{~mm}$.

Short tests were carried out with a fixed sliding distance of $100 \mathrm{~m}$ and changing the applied loads between 1 and $19 \mathrm{~N}$ (limits of the tribometer), in order to define a proper load for the long run test performed until the coating failure occurred. In fact, no precise indications about the load to be used are present in ASTM G 99.

The worn area was monitored during the wear tests without dismounting the sample. In particular, the test was paused every $1000 \mathrm{~m}$ and the track profile was acquired, with a stylus profilometer (Tribotechnique) fixed on the tribometer. The worn area was calculated as the average of the measurements in five different positions of each track.

The profile measurements were executed with a tip radius of $5 \mu \mathrm{m}$ and an applied load of $1 \mathrm{mN}$. Track length was set at $4.8 \mathrm{~mm}$. The instrument was equipped with a Diasoft standard software by Mountains Technologies for the direct worn area calculation.

\section{Results and Discussion}

3.1. Steel Substrate Residual Stress. Figure 1 reports the residual stresses of the steel substrate measured on the samples.

The BS samples show a high compressive stress due to the finishing operations (grinding and polishing). After deposition, the compression decreases probably because of stress relief induced by the high deposition temperature $\left(450^{\circ} \mathrm{C}\right)$. Concerning the $\mathrm{CrN}+\mathrm{MB}$ samples, the microblasting treatment significantly increases the residual stress of the steel substrate, as a function of the applied pressure. Hence, after microblasting, even with the lower pressure, the compressive stress is higher than that of the BS. This effect has been already investigated by the authors in [8]. 


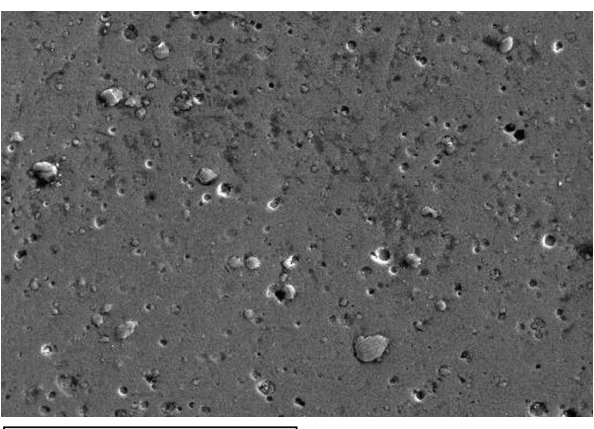

$80 \mu \mathrm{m}$

(a)

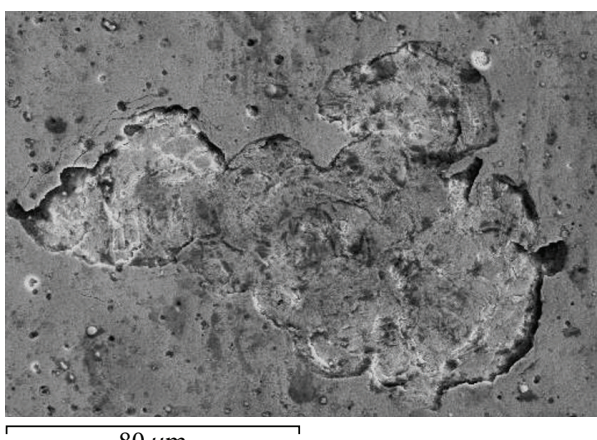

(c)

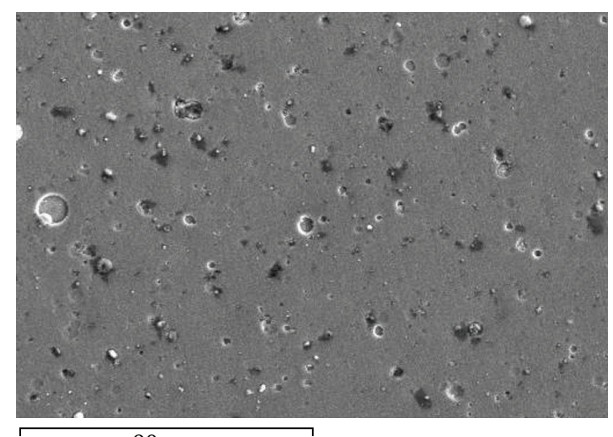

$80 \mu \mathrm{m}$

(b)

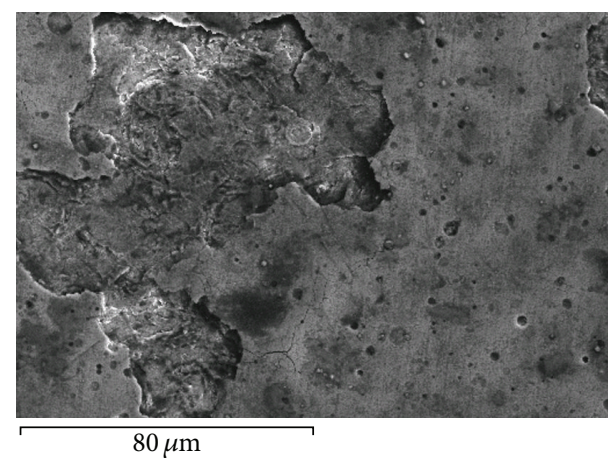

(d)

Figure 2: SEM analyses of the coating of $\operatorname{CrN}$ (a) and $\operatorname{CrN}+\mathrm{MB}$ at 2 bar (b), 3 bar (c), and 6 bar (d).

3.2. Morphological Analysis of the Coatings. In Figure 2, the images of the coatings collected by SEM are shown. CrN samples in as-deposited state are characterized by a high presence of droplets, whose size ranges from 1 to tens of micron (Figure 2(a)). The microblasting treatment seems to be effective in removing the larger droplets (Figure 2(b)). It can be also seen that microblasting performed at higher pressure can locally damage the coating, causing cracks and, in some cases, also detachments (Figures 2(c) and 2(d)). It follows that the proper microblasting pressure has to be defined for each specific coating and substrate, in order to have a good compromise between residual compressive stress and coating soundness.

On the base of these observations, subsequent mechanical, corrosion, and wear investigations were performed only on $\mathrm{CrN}$ and $\mathrm{CrN}+\mathrm{MB}$ with a pressure of 2 bar. This pressure, in fact, guarantees the integrity of the PVD coating, contrary to 3 and 6 bar.

3.3. Hardness and Adhesion. Table 2 shows the HV hardness of the coatings obtained by nanoindentation tests and the scratch tests results.

No significant variations either in the coating hardness or in the critical loads can be detected as a consequence of the microblasting. These results confirm the data reported by the authors elsewhere on different $\mathrm{CrN}$ coatings [8].

It can be concluded that the microblasting treatment at 2 bar is effective in increasing the residual stress of the substrate and in cleaning the CrN surface from the droplets,
TABLE 2: Hardness and scratch tests results.

\begin{tabular}{lcc}
\hline & CrN & CrN + MB (2 bar) \\
\hline HV & $2009 \pm 95$ & $2004 \pm 110$ \\
LC1 & $14.9 \pm 1.5$ & $14.4 \pm 1.5$ \\
LC2 & $50.6 \pm 1.3$ & $49.9 \pm 0.9$ \\
\hline
\end{tabular}

without appreciably affecting the hardness and adhesion of the coating.

3.4. Corrosion Resistance. Figure 3 shows the potentiodynamic curves obtained for the $\mathrm{BS}, \mathrm{CrN}$, and $\mathrm{CrN}+\mathrm{MB}$ 2 bar samples. As expected, the coated samples revealed a better corrosion behavior. Ceramic coatings, in fact, act as a barrier against aggressive environments, because of their higher nobility than metals, reducing the corrodible areas to those regions where the substrate is exposed (e.g., porosity) [20].

Comparing the two coating conditions, it can be observed that the corrosion current density is lower for the $\mathrm{CrN}+$ MB sample of about $15 \%$ (see Table 3). It follows that a lower corrosion occurs on the microblasted sample. The corrosion current density is measured during the tests as sum of the effective corrosion of the substrate and that of the droplets, which are known to act as preferential corrosion sites (Figure 4). Therefore, the coating with less droplets ( $\mathrm{CrN}$ $+\mathrm{MB}$ ) exhibits a lower corrosion current density. 
TABLE 3: Corrosion tests results.

\begin{tabular}{lccccc}
\hline & $\begin{array}{c}\text { Corrosion current density } \\
i_{0}\left[\mathrm{~A} / \mathrm{cm}^{2}\right]\end{array}$ & $\begin{array}{c}\text { Free corrosion potential } \\
E_{0}[\mathrm{~V}]\end{array}$ & $\begin{array}{c}\text { Coating porosity } \\
P[\%]\end{array}$ & $\begin{array}{c}\text { Passivation current density } \\
i_{p}\left[\mathrm{~A} / \mathrm{cm}^{2}\right]\end{array}$ & $\begin{array}{c}\text { Rupture potential } \\
E_{t}[\mathrm{~V}]\end{array}$ \\
\hline $\mathrm{BS}$ & $5.8 \times 10^{-6}$ & -0.59 & 1 & & \\
$\mathrm{CrN}$ & $1.8 \times 10^{-7}$ & -0.39 & $2.6 \times 10^{-5}$ & $7.9 \times 10^{-6}$ & 0.55 \\
$\mathrm{CrN}+\mathrm{MB}$ & $1.5 \times 10^{-7}$ & -0.36 & $2.5 \times 10^{-5}$ & $4.9 \times 10^{-5}$ & 0.37 \\
\hline
\end{tabular}

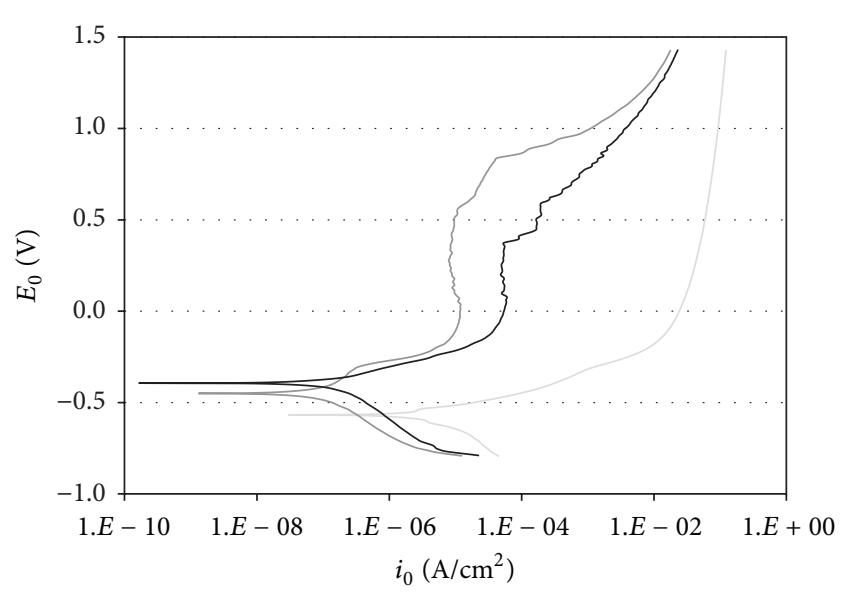

Bare steel

- $\mathrm{CrN}$

$-\mathrm{CrN}+\mathrm{MB}(2$ bar $)$

Figure 3: Potentiodynamic curves of the studied samples.

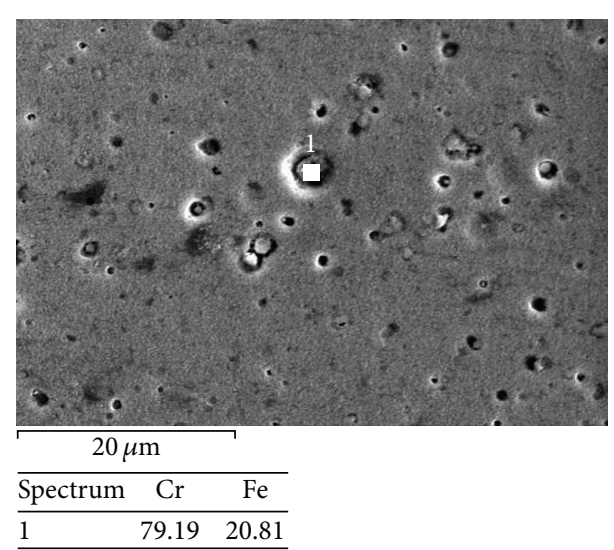

FIgURE 4: Droplet corrosion in CrN coating.

Moreover, $\mathrm{Cr}$ droplets are less noble than CrN; thus, the presence of such defects explains the reduction of the free corrosion potential $\left(E_{0}\right)$.

In Table 3, the calculated porosity level $(P \%)$ is also reported, which represents the fraction of substrate area exposed to the environment. For both $\mathrm{CrN}$ and $\mathrm{CrN}+\mathrm{MB}$ the calculated $P \%$ results are similar, further confirming that the difference in their corrosion behavior is only related to the different amount of droplets.

Additionally, because the porosity level does not increase in the $\mathrm{CrN}+\mathrm{MB}$ coating, it can be concluded that no damage

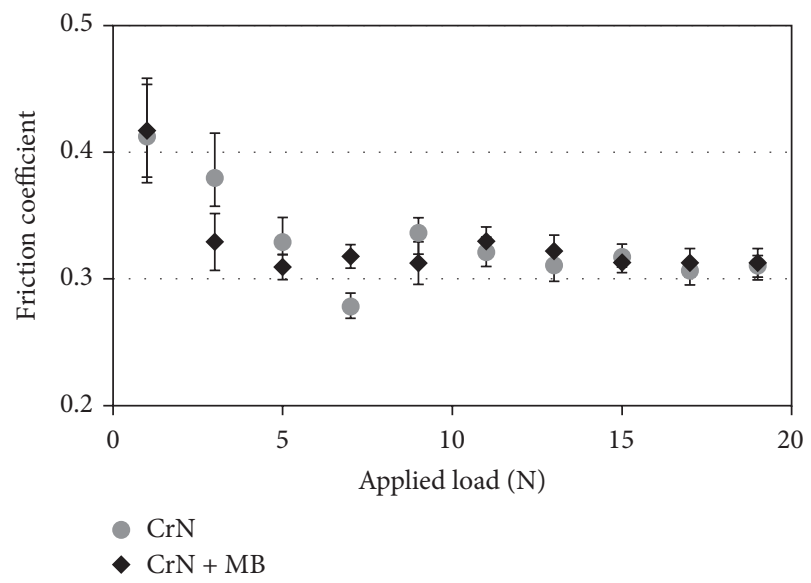

FIGURE 5: Friction coefficient as a function of the applied load (100 m tests).

was introduced by using the chosen microblasting parameters, as already assessed by the SEM analyses (Figure 2).

Considering the passive region, an overturning in the behavior of the coated samples has to be noticed. As reported in Table 3, in fact, in the CrN + MB samples, the passivation current density $\left(i_{p}\right)$ is higher and the rupture potential $\left(E_{t}\right)$ is lower. In these samples corrosion can occur easily due to the lower coating thickness where droplets have been removed by the microblasting.

3.5. Wear Resistance. Figure 5 shows the friction coefficient obtained during the wear tests as a function of the applied load. The reported values were obtained as the mean value of the friction coefficient recorded during each test after the runin (about 1 meter). In both the $\mathrm{CrN}$ and $\mathrm{CrN}+\mathrm{MB}$ samples, increasing the applied load the friction coefficient decreases until it reaches stable values around 0.3 , in agreement with the literature [21]. The wear mechanism is abrasive for both coatings.

To understand the behavior of the friction coefficient, SEM images of the wear tracks were collected for each test condition. After the wear test was performed at $1 \mathrm{~N}$, the droplets are still present and almost undamaged inside the wear track of the CrN samples (Figure 6(a)), notwithstanding the fact that they are softer than the ceramic coating. By increasing the load, as, for instance, at $5 \mathrm{~N}$, the droplets appear flattened on the scar surface (Figure 6(b)). For higher loads, no more droplets can be found on the wear path, as already detectable at $9 \mathrm{~N}$ (Figure 6(c)). 


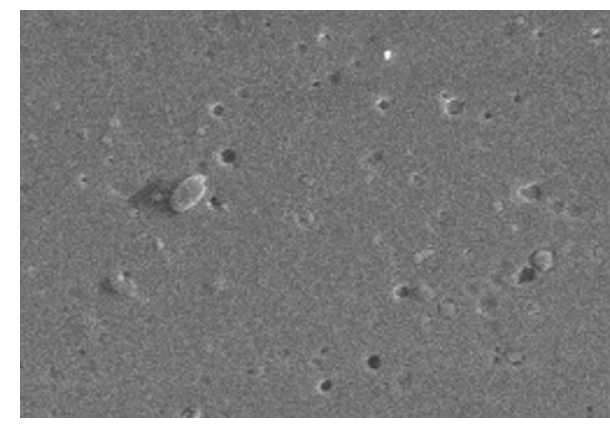

$40 \mu \mathrm{m}$

(a)

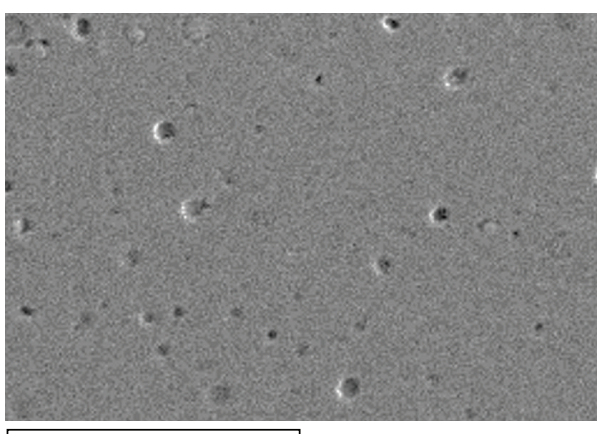

$40 \mu \mathrm{m}$

(c)

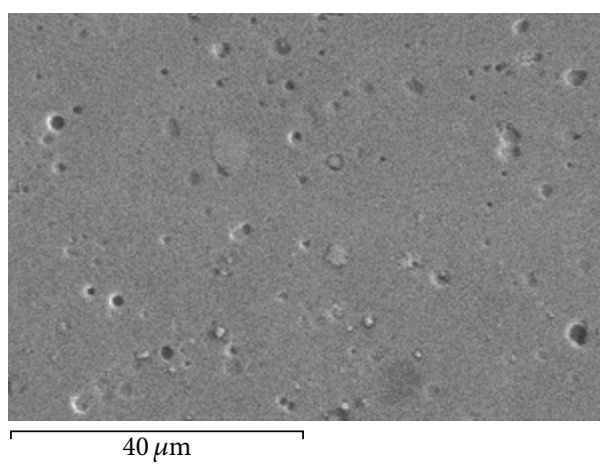

(e)

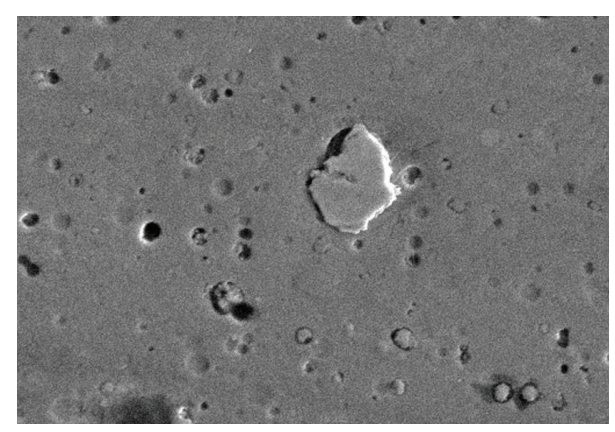

$40 \mu \mathrm{m}$

(b)

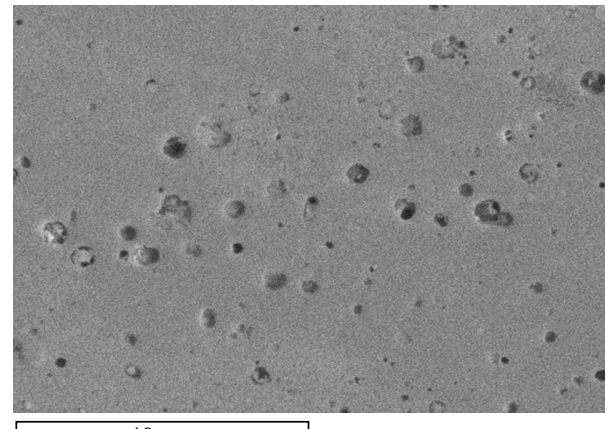

$40 \mu \mathrm{m}$

(d)

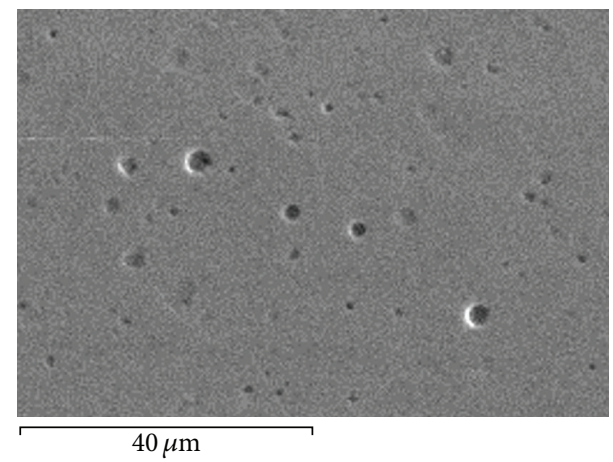

(f)

Figure 6: SEM images of the wear scare of samples $\mathrm{CrN}$ at 1, 5, and $9 \mathrm{~N}$, respectively $(\mathrm{a}, \mathrm{b}, \mathrm{c})$, and of samples $\mathrm{CrN}+\mathrm{MB}$ at 1,5 , and $9 \mathrm{~N}$, respectively (d, e, f). Sliding distance of $100 \mathrm{~m}$.

In the case of $\mathrm{CrN}+\mathrm{MB}$, also at lower loads the wear tracks appear already flat and without droplets (Figures 6(d)$6(f)$ ), thanks to the cleaning effect of the microblasting. In fact, stable friction coefficient values were reached at lower loads than for the $\mathrm{CrN}$ samples.

The long run wear tests were done at $9 \mathrm{~N}$, which is a load able to guarantee the achievement of a stable friction coefficient in both $\mathrm{CrN}$ and $\mathrm{CrN}+\mathrm{MB}$.

Figure 7 reports an example of the friction coefficient measured during the whole tests duration.

It can be clearly seen that the coefficients are similar for both $\mathrm{CrN}$ and $\mathrm{CrN}+\mathrm{MB}$. In particular, the coefficients rapidly increase from values around 0.3 (as in the $100 \mathrm{~m}$ test) to stable values in the range of $0.35-0.45$ till the failure. However, the coating breakdown of the $\mathrm{CrN}$ samples occurs earlier than $\mathrm{CrN}+\mathrm{MB}$. This can be easily identified by the sharp increase in the friction coefficients in Figure 7. The resulting average breaking point distances equal $6690 \pm 136 \mathrm{~m}$ and $8470 \pm 223 \mathrm{~m}$ for the $\mathrm{CrN}$ and $\mathrm{CrN}+\mathrm{MB}$, respectively.

The improved behavior of the coating after microblasting can be also confirmed by the analysis of the worn area (Figure 8).

Before the coating failure, the worn area increases almost linearly with the sliding distance for both coatings but with different slopes (Figure 8). In particular, microblasting seems to reduce the wear during the test.

As already reported, hardness is the same for both coatings (Table 2) as well as the wear track morphologies during tests at $9 \mathrm{~N}$ (Figure 6) and the wear mechanism. It follows that the worn area should be almost the same, contrary to the 


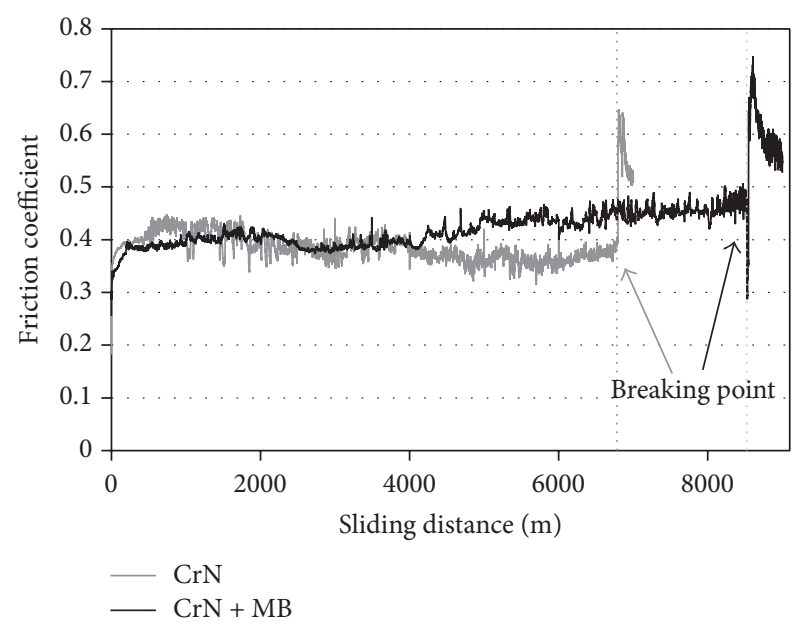

FIgURE 7: Example of friction coefficient curves for long run test.

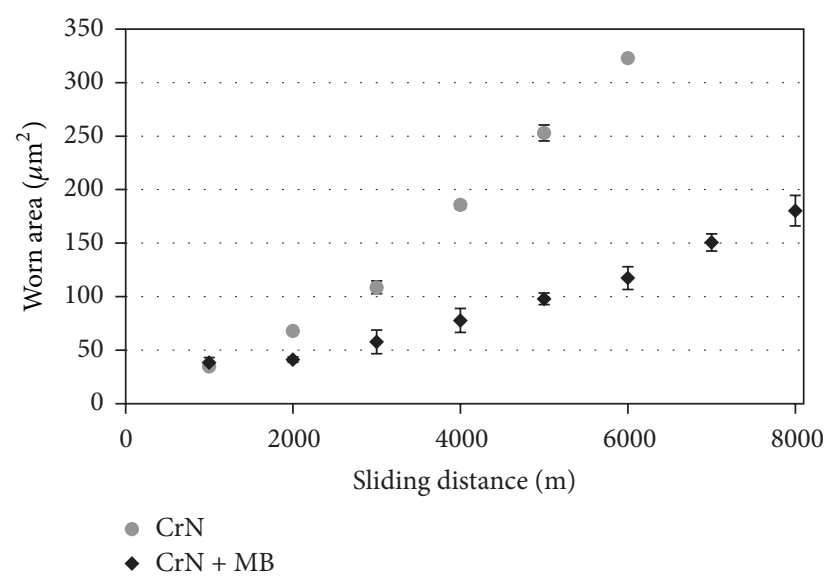

FIGURE 8: Evolution of the wear scare profile.

measurements. This can be explained by the different residual compressive stress, induced by microblasting. As reported in [8], in fact, the compressive residual stress is related to an increased stiffness of the substrate. Consequently, a lower deformation is expected when the substrate is stiffer, that is, in the $\mathrm{CrN}+\mathrm{MB}$ samples.

Hence, the worn area measured during the experiments does not only depend on the effectively removed material, but also depend on the subsidence of the coating into the substrate. The coating is not able to follow the deformation of the substrate, in particular in the CrN samples, causing the earlier failure of the coating.

\section{Conclusions}

In this paper the influence of microblasting applied to CAE CrN coatings on corrosion and wear resistance was investigated. A preliminary study allowed fixing at 2 bar the proper microblasting pressure able to clean the surface from the droplets, without inducing cracks or delaminations.
Subsequent corrosion tests showed that, notwithstanding the improved cleanness of the coating surface, samples after microblasting are less resistant. This is because the corrosion phenomenon occurs more easily where the coating thickness is reduced by the removal of the droplets.

Concerning the wear resistance, a better behavior was assessed as a consequence of the higher compressive residual stress in the steel substrate, that is, higher stiffness, due to the microblasting.

\section{Competing Interests}

The authors declare that they have no competing interests.

\section{Acknowledgments}

The authors are gratefully indebted to V. Sisti from TTN S.p.a. for the coatings deposition, to P. Colombi from CSMT for the nanoindentation and scratch measurement, and to A. Ghidini from Lucchini RS for the steel supply.

\section{References}

[1] L. Montesano, C. Petrogalli, A. Pola, M. Gelfi, V. Sisti, and G. M. La Vecchia, "Corrosion and wear behavior of CAE deposited CrN-PVD coatings," Key Engineering Materials, vol. 577-578, pp. 641-644, 2014.

[2] C. Petrogalli, L. Montesano, M. Gelfi, G. M. La Vecchia, and L. Solazzi, "Tribological and corrosion behavior of CrN coatings: roles of substrate and deposition defects," Surface \& Coatings Technology, vol. 258, pp. 878-885, 2014.

[3] L. A. Dobrzanski, M. Polok, P. Panjan, S. Bugliosi, and M. Adamiak, "Improvement of wear resistance of hot work steels by PVD coatings deposition," Journal of Materials Processing Technology, vol. 155-156, no. 1-3, pp. 1995-2001, 2004.

[4] K. Bobzin, R. Nickel, N. Bagcivan, and F. D. Manz, "PVDCoatings in injection molding machines for processing optical polymers," Plasma Processes and Polymers, vol. 4, supplement 1, pp. S144-S149, 2007.

[5] W.-Y. Ho, C.-H. Shen, C.-L. Chang, and D.-Y. Wang, "Corrosion behaviors of $\mathrm{Cr}(\mathrm{N}, \mathrm{O}) / \mathrm{CrN}$ multi-layered coatings by cathodic arc deposition," Surface and Coatings Technology, vol. 202, no. 4-7, pp. 745-749, 2007.

[6] D. K. Merl, P. Panjan, M. Panjan, and M. Čekada, “The role of surface defects density on corrosion resistance of PVD hard coatings," Plasma Processes and Polymers, vol. 4, no. 1, pp. S613S617, 2007.

[7] S. H. Ahn, J. H. Yoo, Y. S. Choi, J. G. Kim, and J. G. Han, "Corrosion behavior of PVD-grown WC- $\left(\mathrm{Ti}_{1-x} \mathrm{Al}_{x}\right) \mathrm{N}$ films in a $3.5 \% \mathrm{NaCl}$ solution," Surface \& Coatings Technology, vol. 162, no. 2-3, pp. 212-221, 2003.

[8] L. Montesano, A. Pola, M. Gelfi, M. Brisotto, L. E. Depero, and G. M. La Vecchia, "The effect of micro blasting on CAE CrN coatings," Surface Engineering, vol. 29, no. 9, pp. 683-688, 2013.

[9] K.-D. Bouzakis, N. Michailidis, S. Hadjiyiannis et al., "Improvement of PVD coated inserts cutting performance, through appropriate mechanical treatments of substrate and coating surface," Surface and Coatings Technology, vol. 146-147, pp. 443450, 2001. 
[10] F. Klocke, T. Schroeder, E. Bouzakis, and A. Klein, "Manipulation of coating and subsurface properties in reconditioning of WC-Co carbide cutting tools," Surface and Coatings Technology, vol. 202, no. 4-7, pp. 1194-1198, 2007.

[11] K.-D. Bouzakis, G. Skordaris, F. Klocke, and E. Bouzakis, "A FEM-based analytical-experimental method for determining strength properties gradation in coatings after micro-blasting," Surface and Coatings Technology, vol. 203, no. 19, pp. 2946-2953, 2009.

[12] K.-D. Bouzakis, N. Michailidis, G. Skordaris, E. Bouzakis, D. Biermann, and R. M'Saoubi, "Cutting with coated tools: coating technologies, characterization methods and performance optimization," CIRP Annals-Manufacturing Technology, vol. 61, no. 2, pp. 703-723, 2012.

[13] C. Petrogalli, L. Montesano, A. Pola, M. Gelfi, A. Ghidini, and G. M. La Vecchia, "Improvement of fatigue resistance of a tool steel by surface treatments," Procedia Engineering, vol. 109, pp. 154-161, 2015.

[14] S. Baragetti, M. Gelfi, G. M. La Vecchia, and N. Lecis, "Fatigue resistance of $\mathrm{CrN}$ thin films deposited by arc evaporation process on H11 tool steel and 2205 duplex stainless steel," Fatigue and Fracture of Engineering Materials and Structures, vol. 28, no. 7, pp. 615-621, 2005.

[15] N. Lecis, G. M. La Vecchia, M. Boniardi, and F. D’Errico, "Fatigue behavior of duplex-treated samples coated with Cr(C,N) film," Surface and Coatings Technology, vol. 201, no. 6, pp. 2335-2340, 2006.

[16] D. M. Mattox, "Film characterization and some basic film properties," in Handbook of Physical Vapor Deposition (PVD) Processing: Film Formation, Adhesion, Surface Preparation and Contamination Control, p. 595, Noyes, Westwood, NJ, USA, 1998.

[17] G. Berg, C. Friedrich, E. Broszeit, and C. Berger, "Development of chromium nitride coatings substituting titanium nitride," Surface and Coatings Technology, vol. 86-87, no. 1, pp. 184-191, 1996.

[18] B. D. Cullity and S. R. Stock, Elements of X-Ray Diffraction, Prentice Hall, Upper Saddle River, NJ, USA, 3rd edition, 2001.

[19] F. Cai, Q. Yang, X. Huang, and R. Wei, "Microstructure and corrosion behavior of $\mathrm{CrN}$ and $\mathrm{CrSiCN}$ coatings," Journal of Materials Engineering and Performance, vol. 19, no. 5, pp. 721727, 2010.

[20] L. Montesano, M. Gelfi, A. Pola, P. Colombi, and G. M. La Vecchia, "Corrosion resistance of CrN PVD coatings: comparison among different deposition techniques," Metallurgia Italiana, vol. 105, no. 2, pp. 3-11, 2013.

[21] E. Martinez, J. Romero, A. Lousa, and J. Esteve, "Wear behavior of nanometric CrN/Cr multilayers," Surface and Coatings Technology, vol. 163-164, pp. 571-577, 2003. 

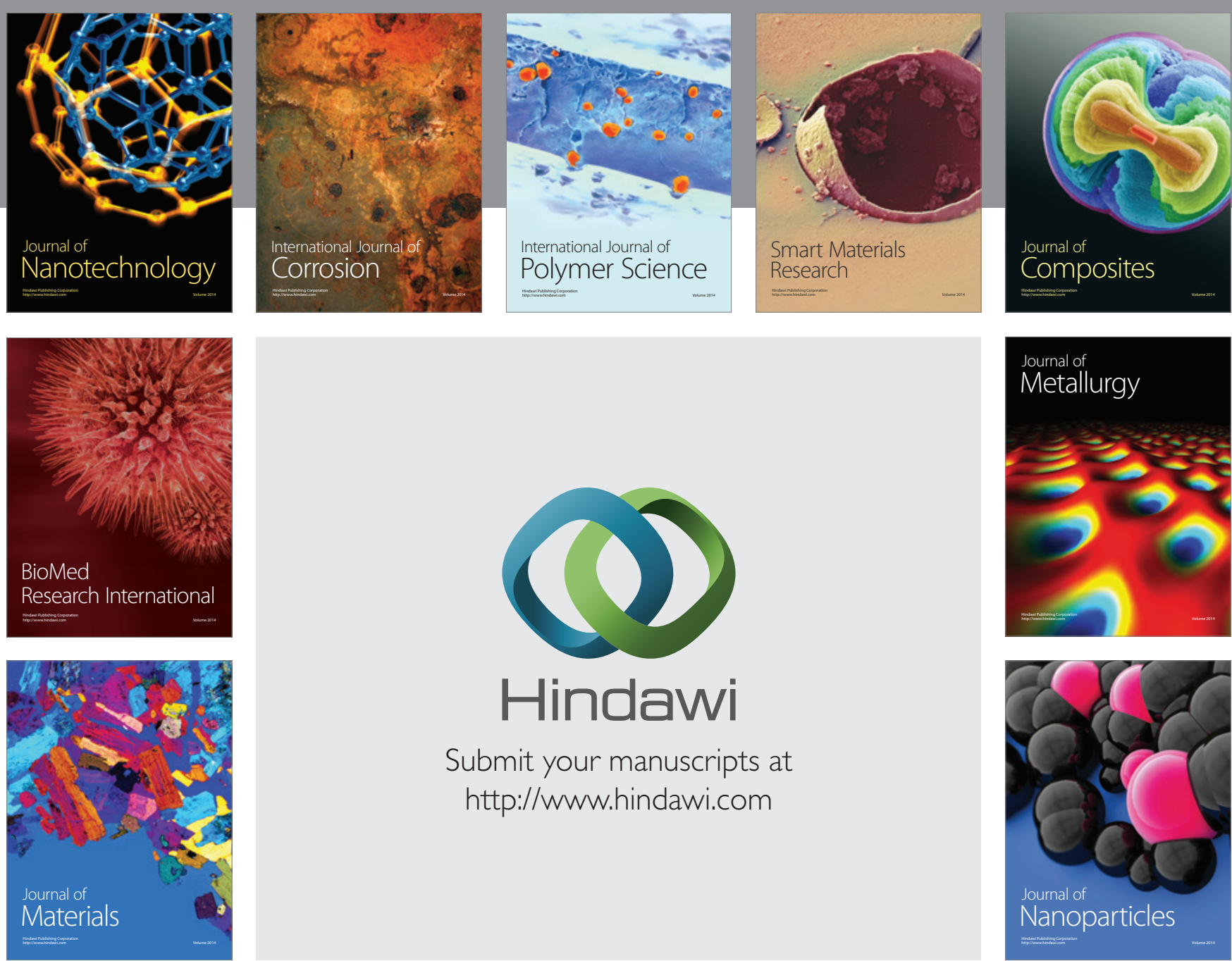

\section{Hindawi}

Submit your manuscripts at

http://www.hindawi.com

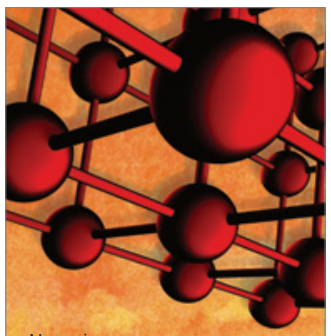

Materials Science and Engineering
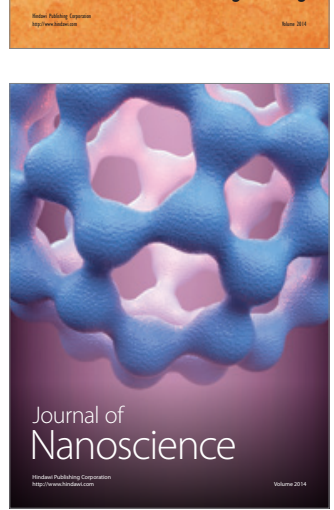
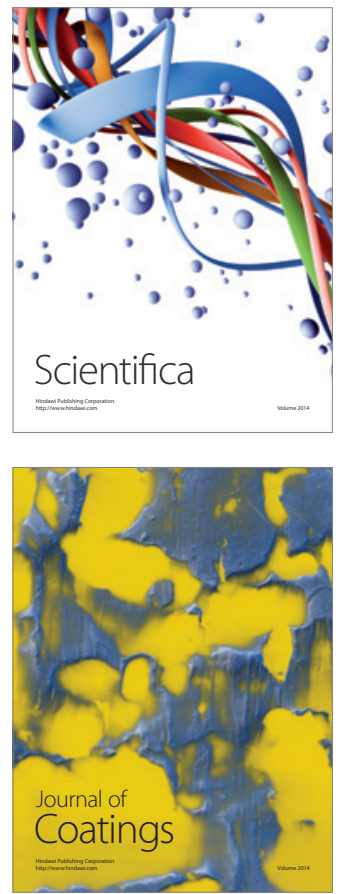
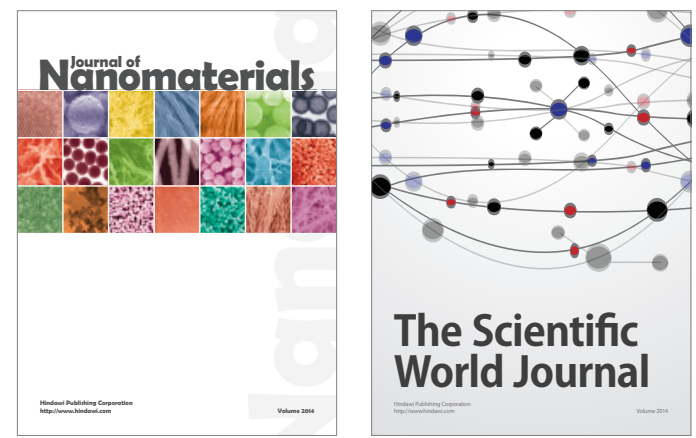

The Scientific World Journal
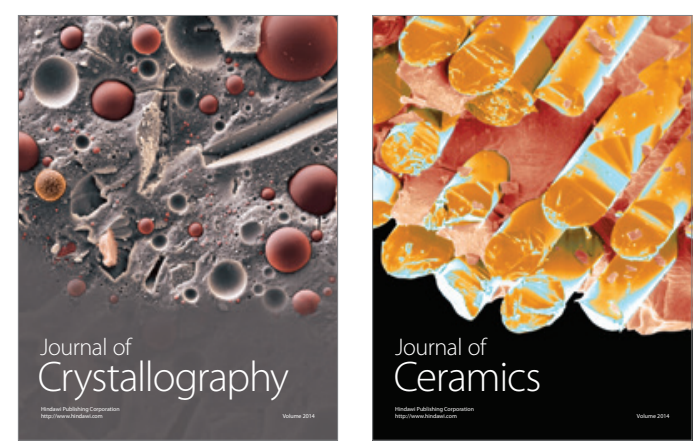
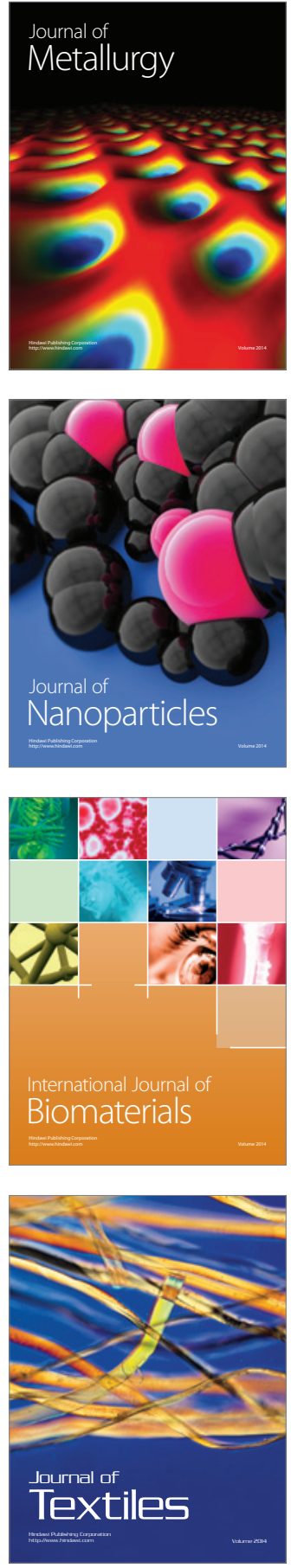